\title{
EL TRATADO SOBRE LA CARTA DE LA ENERGÍA Y EL ARBITRAJE INTERNACIONAL DE INVERSIONES EN FUENTES DE ENERGÍAS RENOVABLES. CASO CHARANNE B.V. Y CONSTRUCTION INVESTMENTS S. A.R. L. VS. REINO DE ESPAÑA
}

\author{
VÍCTOR RAFAEL HERNÁNDEZ-MENDIBLE ${ }^{1}$ \\ Universidad del Rosario (Colombia) \\ victorhernandezmendible@gmail.com
}

Cómo citar/Citation

Hernández-Mendible, V. R. (2017).

El Tratado sobre la Carta de la Energía y el arbitraje internacional de inversiones en fuentes de energías renovables. Caso Charanne B. V.

y Construction Investments S. A. R. L. vs. Reino de España. Revista de Administración Pública, 202, 223-253. doi: https://doi.org/10.18042/cepc/rap.202.08

Resumen

Este estudio analiza cómo, después de que el Estado diseñara a comienzos de siglo las políticas públicas de fomento de las inversiones para incrementar el aprovechamiento de las fuentes de energías renovables, sobrevino la crisis económica mundial que condujo a la modificación de tales políticas, lo que se materializó en una sucesiva reforma de la regulación que alteró las condiciones iniciales de las inversiones, lo que pudo comprometer la responsabilidad del Estado, todo ello en el contexto de las obligaciones contraídas en el Tratado sobre la Carta de la Energía. Esto condujo a los inversionistas a intentar demandas de responsabilidad ante los tribunales nacionales y los tribunales internacionales arbitrales, cuyas decisiones serán analizadas.

1 Profesor de Derecho Administrativo. Profesor invitado del núcleo básico en la Maestría en Derecho Energético y Sustentabilidad en la Universidad Autónoma de Nuevo León (México). www.hernandezmendible.com. 


\section{Palabras clave}

Tratado sobre la Carta de la Energía; energías renovables; políticas de fomento; arbitraje internacional.

\section{Abstract}

This paper analyze how after the State designed, at the beginning of the century, public policies to promote investment and increase renewable energy sources, it appeared the global economic crisis that led to the reform of such policies, which was materialized in a subsequent amendment of the regulation that changed the original terms of investments, and put at risk the State's responsibility in relation with its obligations under the Treaty on the Energy Charter, which led investors to try liability claims before national courts as well as international arbitration, whose decisions will analyzed.

\section{Keywords}

Energy Charter Treaty; renewable energy; promotion policies; international arbitration. 


\section{SUMARIO}

I. INTRODUCCIÓN. II. EL DERECHO ESTATAL Y LAS REFORMAS REGULATORIAS:

1. El marco regulatorio inicial y las reformas. 2. Los criterios establecidos por los tribunales nacionales sobre el Tratado sobre la Carta de la Energía: 2. 1. La posición del Tribunal Constitucional en los casos sometidos a su consideración. 2.2. La posición del Tribunal Supremo en los casos sometidos a su consideración. 3. Las implicaciones de los fallos respecto a los generadores mediante fuentes renovables. III. EL LAUDO ARBITRAL QUE APLICA EL TRATADO SOBRE LA CARTA DE LA ENERGÍA: 1. Las pretensiones de las partes. 2. La fundamentación del laudo: 2.1. Los medios eficaces para la tramitación de demandas. 2.2. La expropiación indirecta. 2.3. El trato justo y equitativo. 3. La decisión. 4. El voto disidente. IV. EL OTRO LAUDO ARBITRAL QUE APLICA EL TRATADO SOBRE LA CARTA DE LA ENERGÍA. V. CONSIDERACIONES FINALES.

\section{INTRODUCCIÓN}

El 13 de diciembre de 2007 los entonces países miembros de la Unión Europea alcanzaron un nuevo tratado de reforma ${ }^{2}$, que se denomina Tratado de Lisboa y que entró en vigor el 1 de diciembre de 2009.

Este instrumento tiene la particularidad de modificar tanto el Tratado de la Unión Europea como el Tratado constitutivo de la Comunidad Europea, que pasó a denominarse Tratado de Funcionamiento de la Comunidad Europea, pero sin llegar a sustituirlos.

Este nuevo Tratado vino a fortalecer el marco normativo y los instrumentos jurídicos para dar mayor solidez a la Unión Europea, hacerla más democrática, transparente y eficaz; de renovados derechos, libertades y valores; de solidaridad y seguridad; y el texto debe contribuir a consolidar su presencia y liderazgo a

2 Tratado de Lisboa, DOUE, de 17 de diciembre de 2007. 
escala mundial. Además se incluyó una cláusula de procedimiento de retiro de la Unión, para el caso en que un Estado miembro así lo resolviera ${ }^{3}$.

De especial interés a los efectos de este trabajo resulta la novedad del establecimiento de los fundamentos jurídicos para el desarrollo de la política energética, así como las políticas sobre el ambiente y el cambio climático ${ }^{4}$. Esta es

3 Esta cláusula será activada por vez primera, luego que el día 23 de junio de 2016, oportunidad en que el Reino Unido efectuó la consulta a la población, para que optasen entre seguir en la Unión Europea o retirarse de la misma, la mayoría de los participantes en la consulta - aunque por un estrecho margen - se expresaron en favor de la opción del retiro. En efecto, a favor del brexit se pronunciaron 17410742 personas, que representan el 51,9\%, y a favor de permanecer en la Unión se manifestaron 16577342 personas, que representan el 48,1\%. El portal BBC Mundo tituló al día siguiente: «El Brexit gana el referendo: Reino Unido elige salir de la Unión Europea. ¿Qué pasa ahora?». Se debe señalar que existe un antecedente de retiro de la Comunidad Económica Europea de parte de Groenlandia, un territorio autónomo, pero que depende del Reino de Dinamarca, lo que ocurrió en 1982, momento para el cual no se encontraba en vigor el Tratado de Lisboa. El portal BBC Mundo el día 6 de septiembre de 2016 tituló: «Brexit: las duras lecciones para Reino Unido de Groenlandia, el único territorio que ha abandonado la Unión Europea». Finalmente, el portal BBC Mundo informa el día 28 de marzo de 2017: «Brexit: Theresa May firma la carta que dará inicio a la salida de Reino Unido de la Unión Europea»

4 El título XX, Energía, artículo 176A del Tratado de Lisboa, estableció:

«1. En el marco del establecimiento o del funcionamiento del mercado interior y atendiendo a la necesidad de preservar y mejorar el medio ambiente, la política energética de la Unión tendrá por objetivo, con un espíritu de solidaridad entre los Estados miembros:

a) garantizar el funcionamiento del mercado de la energía;

b) garantizar la seguridad del abastecimiento energético en la Unión;

c) fomentar la eficiencia energética y el ahorro energético así como el desarrollo de energías nuevas y renovables; y

d) fomentar la interconexión de las redes energéticas.

2. Sin perjuicio de la aplicación de otras disposiciones de los Tratados, el Parlamento Europeo y el Consejo establecerán, con arreglo al procedimiento legislativo ordinario, las medidas necesarias para alcanzar los objetivos mencionados en el apartado 1. Dichas medidas se adoptarán previa consulta al Comité Económico y Social y al Comité de las Regiones. No afectarán al derecho de un Estado miembro a determinar las condiciones de explotación de sus recursos energéticos, sus posibilidades de elegir entre distintas fuentes de energía y la estructura general de su abastecimiento energético, sin perjuicio de la letra c) del apartado 2 del artículo 175 .

3. No obstante lo dispuesto en el apartado 2, el Consejo, con arreglo a un procedimiento legislativo especial, por unanimidad y previa consulta al Parlamento Europeo, establecerá las medidas mencionadas en ese apartado cuando sean esencialmente de carácter fiscal». 
considerada una nueva competencia de la Unión Europea, que concurre con las competencias de los Estados miembros sobre sus recursos energéticos ${ }^{5}$.

Lo señalado no constituye óbice para que se hayan aprobado por la Unión Europea los distintos bloques o paquetes normativos - dentro del ámbito de sus competencias- sobre las energías ${ }^{6}$.

Aunque no corresponde extenderse en este asunto por exceder los límites de este trabajo, es bueno dejar sentado que con base en el principio de libre competencia que inspira el desempeño de los mercados europeos, a los fines de evitar que se falsee la competencia y se afecte el comercio, en principio están prohibidas las ayudas económicas públicas ${ }^{7}$, considerándose únicamente compatibles con los mercados aquellas que sean de carácter excepcional, de vigencia temporal, en el supuesto de que sean estrictamente necesarias y que puedan justificarse razonablemente ante las instituciones de la Unión Europea $^{8}$. Conforme a ello es que se han admitido las ayudas estatales para el caso del fomento del aprovechamiento de las fuentes de energías renovables?

5 A. Embid Irujo (2016), «Energías renovables, medio ambiente y mercado interior de la Energía: Algunas reflexiones en la víspera del «cuarto paquete» sobre la Unión de la Energía", Revista Argentina de Derecho de la Energía, Hidrocarburos y Minería, 9, pág. 72.

6 I. del Guayo (2014), «El marco jurídico internacional comunitario de las energías renovables», en J. F. Alenza García (dir.), La regulación de las energías renovables ante el cambio climático, Pamplona: Thomson-Reuters Aranzadi (págs. 35-58).

7 Artículo 107.1 del Tratado de Funcionamiento de la Unión Europea.

8 Artículos 107.2 y 107.3 del Tratado de Funcionamiento de la Unión Europea.

9 Inicialmente el fomento de las fuentes de energías renovables se estableció en la Directiva 2001/77/CE, relativa a la promoción de la electricidad generada a partir de fuentes de energías renovables en el mercado interior de la electricidad, DO L 283, de 27 de octubre de 2001; y en la Directiva 2003/30/CE, relativa al fomento del uso de biocarburantes u otros combustibles renovables en el transporte, DO L 123, de 17 de mayo de 2003; que fueron derogadas por la Directiva 2009/28/CE del Parlamento Europeo y del Consejo, de 23 de abril de 2009, relativa al fomento del uso de energía procedente de fuentes renovables, DOUE 140, de 5 de junio de 2009, cuyo artículo 1 dispone que: «La presente Directiva establece un marco común para el fomento de la energía procedente de fuentes renovables. Fija objetivos nacionales obligatorios en relación con la cuota de energía procedente de fuentes renovables en el consumo final bruto de energía y con la cuota de energía procedente de fuentes renovables en el transporte. Establece normas relativas a las transferencias estadísticas entre Estados miembros, los proyectos conjuntos entre Estados miembros y con terceros países, las garantías de origen, los procedimientos administrativos, la información y la formación, y el acceso a la red eléctrica para la energía procedente de fuentes renovables. Define criterios de sostenibilidad para los biocarburantes y biolíquidos»; y ha sido complementada 
No obstante el anterior contexto europeo, lo que motiva este análisis no se refiere a un estudio sobre la compatibilidad del régimen nacional de las energías con el régimen de la Unión Europea, sino al posible incumplimiento por un Estado miembro de la Unión Europea, que al modificar su régimen especial de generación de electricidad, mediante el aprovechamiento de las fuentes renovables, pudo incurrir en desconocimiento de las obligaciones que se tienen establecidas en los tratados que garantizan la protección de las inversiones — como el Tratado sobre la Carta de la Energía ${ }^{10}$ —, lo que podría derivar en una potencial reclamación patrimonial de indemnización por los eventuales afectados y en una hipotética condena por los órganos jurisdiccionales nacionales o de los tribunales arbitrales.

Ello demuestra que en este especial escenario de compromisos internacionales tiene particular relevancia el Tratado sobre la Carta de la Energía ${ }^{11}$, que ha servido de instrumento jurídico para valorar los primeros casos en que algunos Estados integrantes de la Unión Europea en ejercicio de su soberanía sobre sus recursos, luego de desarrollar una política de fomento de la inversión en la actividad de generación, mediante el aprovechamiento de las fuentes de energías renovables, resolvieron inicialmente cambiar los estímulos otorgados y posteriormente eliminarlos, por lo que aquellos inversionistas que se consideraron afectados en sus derechos, decidieron acudir en unos casos a los órganos jurisdiccionales nacionales, y en otros, decantarse por utilizar los

recientemente con las directrices sobre ayudas estatales en materia de protección del medio ambiente y energía 2014-2020, DOUE C 200/1, de 28 de junio de 2014. Tratado sobre la Carta de la Energía, de 17 de diciembre de 1994.

11 La Decisión 98/181/CE, CECA y Euratom, del Consejo y de la Comisión de 23 de septiembre de 1997, relativa a la conclusión por parte de las Comunidades Europeas, del Tratado sobre la Carta de la Energía y el Protocolo de la Carta de la Energía sobre la eficacia energética y los aspectos medioambientales relacionados, DO L N ${ }^{\circ} 069$, de 09 de marzo de 1998, estableció en el artículo 1 que: «Quedan aprobados, en nombre de la Comunidad Europea del Carbón y del Acero, de la Comunidad Europea y de la Comunidad Europea de la Energía Atómica, el Tratado sobre la Carta de la Energía y el Protocolo de la Carta de la Energía sobre la eficacia energética y los aspectos medioambientales relacionados (denominado en lo sucesivo "el Protocolo de la Carta de la Energía”). Se adjuntan a la presente Decisión los textos del Tratado sobre la Carta de la Energía y del Protocolo de la Carta de la Energía»; luego será modificada por la Decisión 2001/595/CE del Consejo, de 13 de julio de 2001, relativa a la aprobación por la Comunidad Europea de la enmienda a las disposiciones comerciales del Tratado sobre la Carta de la Energía, DO N L 209, de 02 de agosto de 2001, que dispone en el artículo 1, lo siguiente: "Queda aprobada en nombre de la Comunidad Europea la enmienda a las disposiciones comerciales del Tratado sobre la Carta de la Energía». 
medios de resolución de conflictos que reconoce el referido Tratado ${ }^{12,13}$, a los fines de obtener una compensación.

En aras de una mayor claridad en la exposición de las ideas, el presente trabajo se dividirá en los siguientes aspectos: se realizará un estudio del derecho estatal y las reformas regulatorias en el sector energético de las renovables (II); se efectuará el análisis del laudo arbitral que aplica el Tratado sobre la Carta de la Energía (III); se mencionará el otro laudo arbitral que aplica el Tratado sobre la Carta de la Energía (IV); y se formularán las consideraciones finales $(\mathrm{V})$.

\section{EL DERECHO ESTATAL Y LAS REFORMAS REGULATORIAS}

En el contexto de los derechos nacionales, cada uno de los Estados que hacen parte de la Unión Europea ha adoptado sus políticas de promoción y estímulo al desarrollo y aprovechamiento de las tecnologías y fuentes de energías renovables y, con base en sus fortalezas en los recursos estratégicos, han resuelto a cuáles aplicarles políticas de fomento y ayudas estatales.

\section{EL MARCO REGULATORIO INICIAL Y LAS REFORMAS}

En el caso de España, se expidió el Real Decreto 661/2007, de 25 de mayo, que antecedió a la entrada en vigor de la Ley 54/1997, de 27 de noviembre, del sector eléctrico; y que fue seguida por el Real Decreto 1578/2008, de 26 de septiembre, orientados a fomentar la generación de energía eléctrica en régimen especial, mediante el aprovechamiento de las fuentes de energías renovables, en concreto la solar fotovoltaica.

En función de esto, varios interesados resolvieron invertir en el sector, mediante la constitución de empresas mercantiles que tendrían por objeto la actividad de generación, en los términos previstos en dicho marco regulatorio.

12 C. de los Santos, S. Arana y J. L. Iglesias (2011), «Arbitraje Internacional sobre el Tratado de la Carta de la Energía: La vía del inversor extranjero», Cuaderno de Energía, 30, págs. 5-10.

13 Para diciembre de 2016, existían aproximadamente 101 casos sometidos a arbitraje internacional, conforme al Tratado sobre la Carta Internacional de la Energía y de ellos 30 han sido planteados contra el Reino de España; situación que, a finales de 2015, lo había convertido en el Estado contra quien cursaban más demandas arbitrales. Así lo informaba El Periódico de la Energía, el 15 de noviembre de 2015, bajo el título «Espańa supera a Venezuela y se convierte en el país con más demandas judiciales por inversores extranjeros del mundo». 
No obstante, consecuencia de la crisis económica mundial y en particular de su impacto en Europa, el Estado se vio en la necesidad de efectuar reformas y, entre ellas, el sector de las energías renovables experimentó un sustancial cambio en la política de fomento de generación de energía eléctri$\mathrm{ca}$, a través de la fuente solar fotovoltaica ${ }^{14}$. Ello tuvo lugar a través del Real Decreto 1003/2010, de 5 de agosto; del Real Decreto 1565/2010, de 19 de noviembre; del Real Decreto 1614/2010, de 8 de diciembre, y del Real Decreto Ley 14/2010, de 23 de diciembre.

Posteriormente, se efectuaron otras modificaciones a través del Real Decreto Ley $1 / 2012$, de 22 de enero ${ }^{15}$; de la Ley 15/2012, de 27 de diciembre y del Real Decreto Ley 2/2013, de 1 de febrero.

A estos le seguirán finalmente la eliminación de los incentivos, en el Real Decreto Ley 9/2013, de 12 de julio; la nueva Ley 24/2013, de 26 de diciembre, del sector eléctrico; y el Real Decreto 413/2014, de 6 de junio, que terminará de regular la actividad de producción de energía eléctrica por fuentes de energías renovables, cogeneración y residuos.

Las antes mencionadas reformas han sido objeto de impugnación y de reclamos de naturaleza patrimonial a nivel nacional - porque los inversionistas nacionales no tienen acceso al arbitraje internacional-, por parte de quienes se han considerado afectados, que han acudido a los órganos jurisdiccionales a través de la interposición de recursos de inconstitucionalidad y de demandas contencioso-administrativas que contienen pretensiones de anulación y de condena.

\section{LOS CRITERIOS ESTABLECIDOS POR LOS TRIBUNALES NACIONALES SOBRE EL TRATADO SOBRE LA CARTA DE LA ENERGÍA}

A los efectos de este epígrafe, se procederá a analizar lo expresado aproximadamente en más de quince de fallos del Tribunal Constitucional y el Tribunal Supremo, a los fines de ver la posición de estos Tribunales nacionales con respecto a la aplicación del Tratado sobre la Carta de la Energía, que constituye el principal objeto de estas reflexiones.

En esencia, los argumentos presentados por los demandantes ante los órganos jurisdiccionales nacionales son los siguientes: que se ha incurrido en una transgresión del principio de igualdad jurídica; se produjo una aplicación re-

14 A. Embid Irujo (2012), «El derecho público de la crisis económica», en A. Blasco Esteve (coord.), El derecho público de la crisis económica. Transparencia y Sector Público. Hacia un nuevo Derecho Administrativo (págs. 36-54), Madrid: INAP.

15 I. del Guayo (2012), «Seguridad jurídica y cambios regulatorios», Revista Española de Derecho Administrativo, 156, págs. 217-254. 
troactiva de las nuevas normas; se realizó un desconocimiento de los principios de seguridad jurídica y confianza legítima; se transgredió el principio de interdicción de la arbitrariedad de los poderes públicos y se efectuó una alteración intolerable del principio de la rentabilidad razonable. Algunas demandas han invocado el incumplimiento de ordenamiento jurídico comunitario y además la violación de las disposiciones del Tratado sobre la Carta de la Energía.

Dado que el análisis desde la perspectiva del derecho nacional ha sido efectuado de manera prolija por la doctrina científica, que ha sido notablemente crítica con las sentencias pronunciadas ${ }^{16}$, el presente análisis se circunscribirá a destacar lo resuelto en los fallos y se hará especial referencia a aquellos que se han pronunciado sobre el Tratado sobre la Carta de la Energía.

\subsection{La posición del Tribunal Constitucional en los casos sometidos a su consideración}

A partir de los primeros casos sometidos a su competencia, el Tribunal Constitucional en Pleno, mediante Sentencia 96/2014, de 12 de junio, resuelve desestimar el recurso de inconstitucionalidad interpuesto por el Consejo de Gobierno de la Comunidad Autónoma de la Región de Murcia contra la disposición adicional primera, la disposición transitoria segunda y la disposición final primera del Real Decreto Ley 14/2010, de 23 de diciembre, por el que se establecieron medidas urgentes para la corrección del déficit tarifario del sector eléctrico, mediante la modificación del régimen retributivo de las instalaciones de tecnología solar fotovoltaica. Este criterio fue reiterado por el propio Tribunal Constitucional en Sentencia 109/2014, de 26 de junio.

Luego el Tribunal Constitucional en Pleno, en Sentencia 183/2014, de 6 de noviembre, resolvió el recurso de inconstitucionalidad promovido por el Consejo de Gobierno de la Junta de Andalucía en relación con diversos preceptos de la Ley 15/2012, de 27 de diciembre, de medidas fiscales para la sostenibilidad energética, el Real Decreto Ley 29/2012, de 28 de diciembre, de mejora de gestión y protección social en el sistema especial para empleados de hogar y otras medidas de carácter económico y social; y del Real Decreto Ley $2 / 2013$, de 1 de febrero, de medidas urgentes en el sistema eléctrico y en el

16 I. Ruiz Olmo (2014), «Las renovables ante los recientes cambios normativos: el episodio jurisprudencial del RD 1565/2010, que modifica la tarifa retributiva de la energía fotovoltaica», Actualidad Jurídica Ambiental, 33, págs. 1-28; J. F. Alenza García (2016), «Las energías renovables ante la fugacidad legislativa: la mitificación de los principios de (in)seguridad jurídica y de (des)confianza legítima: [a propósito de la stc 270/2015 sobre el nuevo sistema retributivo de las energías renovables]», Actualidad Jurídica Ambiental, 55, págs. 1-19. 
sector financiero. En esa ocasión declaró la pérdida sobrevenida del objeto del recurso, en lo que se refiere a la vulneración del artículo 9.3 de la Constitución española, del artículo 8 del Real Decreto Ley 29/2012, de 28 de diciembre, de mejora de gestión y protección social en el sistema especial para empleados de hogar y otras medidas de carácter económico y social, y de los artículos 1, apartados 1, 2, 5, 7, 8, 9 y 10 del artículo 2, 3 y la disposición adicional única del Real Decreto Ley 2/2013, de 1 de febrero, de medidas urgentes en el sistema eléctrico y en el sector financiero y desestimó el resto de las pretensiones. Este criterio fue reiterado por el propio Tribunal Constitucional en Sentencia 28/2015, de 19 de febrero.

Posteriormente, el Tribunal Constitucional en Pleno, en Sentencia 48/2015, de 5 de marzo, resolvió el recurso de inconstitucionalidad interpuesto por la Xunta de Galicia, contra el Real Decreto Ley 1/2012, de 27 de enero, por el que se procede a la suspensión de los procedimientos de preasignación de retribución y a la supresión de los incentivos económicos para nuevas instalaciones de producción de energía eléctrica a partir de cogeneración, fuentes de energías renovables y residuos. En este caso volvió a declarar la pérdida sobrevenida del objeto del recurso, en lo que se refiere a la vulneración del artículo 9.3 de la Constitución española por parte del Real Decreto Ley 1/2012, de 27 de enero y desestimó el resto de las pretensiones. Este criterio fue reiterado por el propio Tribunal Constitucional en Sentencia 105/2015, de 28 de mayo.

Finalmente, el Tribunal Constitucional en Pleno, en Sentencia 270/2015, de 17 de diciembre, resolvió desestimar el recurso de inconstitucionalidad interpuesto por el Consejo de Gobierno de la Comunidad Autónoma de la Región de Murcia contra el artículo 1, apartados 2 y 3; disposición adicional primera; disposición transitoria tercera y disposición final segunda del Real Decreto Ley 9/2013, de 12 de julio, por el que se adoptan medidas urgentes para garantizar la estabilidad financiera del sistema eléctrico ${ }^{17}$. Los fundamentos jurídicos de este fallo se reiteran en las Sentencias de 19/2016, de 4 de febrero, 29/2016, de 18 de febrero, 30/2016, de 18 de febrero, y 61/2016, de 17 de marzo.

Ahora bien, en lo que respecta a la pretensión de que se declare la violación del Tratado sobre la Carta de la Energía, la Sentencia 270/2015, de 17 de diciembre — ratificada por la Sentencia 61/2016, de 17 de marzo—, resolvió este alegato en los términos siguientes:

17 Sobre la insatisfacción argumentativa de la sentencia se expresa críticamente T. de la Quadra Salcedo (2016), «Riesgo regulatorio y contractualización de la regulación por operadores y poderes públicos», Riesgo Regulatorio en las energías renovables II, págs. 29-79 (págs. 48-50), Pamplona: Thomson Reuters-Aranzadi. 
En primer lugar, procede advertir que este Tribunal ha declarado reiteradamente que los tratados internacionales no constituyen por sí mismos parámetro de contraste para valorar la posible inconstitucionalidad de las leyes, pues «la supuesta contradicción de los tratados por las leyes o por otras disposiciones normativas posteriores no es cuestión que afecte a la constitucionalidad de éstas y que, por tanto, deba ser resuelto por el Tribunal Constitucional (STC 49/1988, fundamento jurídico 14 in fine), sino que como puro problema de selección del derecho aplicable al caso concreto, su resolución corresponde a los órganos judiciales en los litigios de que conozcan" (SSTC 28/1991, de 14 de febrero, FJ 5, y 207/2013, de 5 de diciembre, FJ 4). En suma, «no corresponde a este Tribunal determinar la compatibilidad o no de un precepto legal con un tratado internacional, ni éstos pueden erigirse en normas fundamentales y criterios de constitucionalidad» (STC 142/1993, de 22 de abril, FJ 3).

En ese sentido tampoco la incorporación de un tratado al ordenamiento jurídico interno, tras su ratificación y publicación oficial, determina - como pretenden los recurrentes - la supuesta vulneración del principio de jerarquía normativa, puesto que la "garantía de la jerarquía normativa proscribe que una norma de rango inferior contravenga lo dispuesto en una de rango superior. Sin embargo, si el criterio de enjuiciamiento en un proceso de constitucionalidad viene proporcionado por la Constitución y, eventualmente, por las normas que integran el bloque de constitucionalidad, dado que, por definición, en todo recurso de inconstitucionalidad subyace un problema de jerarquía normativa, resulta que tal jerarquía no es un canon idóneo para esta labor. La apreciación de contradicción entre un texto legal y la Constitución no entrańa una mera transgresión por norma de rango inferior de lo establecido en otra de rango superior, sino pura y simplemente, la inconstitucionalidad de la norma con rango de ley» (SSTC 91/1998, de 23 de abril, FJ 2, y 198/2012, de 26 de noviembre, FJ 2).

Si bien es cierto que la Carta de la Energía contempla la necesidad de dotar de seguridad y permanencia a las inversiones en energías renovables y la prohibición de adoptar medidas que afecten a dichas inversiones con efectos equivalentes a la expropiación, lo que el recurrente pretende plantear en realidad es una cuestión relacionada con el sistema de fuentes, en particular con el principio de jerarquía normativa. En modo alguno se argumenta sobre el fondo del asunto, esto es, de qué forma las normas que cuestiona contravendrían las reglas del Tratado y, sobre todo, cuáles serían las consecuencias de dicha contravención, a efectos de su enjuiciamiento en sede constitucional. Por eso no se ha levantado la carga alegatoria que pesa sobre quien pretende la declaración de inconstitucionalidad de una norma con rango de ley, pues el recurso carece en este punto de la mínima fundamentación que permita a este Tribunal inferir las razones por las que el recurrente considera que la norma legal impugnada infringe la Constitución. La demanda se limita a hacer referencia al contenido de los arts. 10 y 13 del Tratado sobre la carta de la energía, afirmando posteriormente que «el Estado español, 
con la aprobación del Real Decreto-ley 9/2013, ha incumplido sus obligaciones contraídas con inversores extranjeros...», decisión que, a su entender, implica un incumplimiento del mencionado Tratado que comportaría como consecuencia la infracción de los principios de jerarquía normativa y de seguridad jurídica. Esa infracción aparece únicamente mencionada, ya que la afirmación del recurrente no viene acompañada de la necesaria argumentación específica que permita conocer las razones por las cuales entienden que las disposiciones cuestionadas vulneran el orden constitucional, sin que esta insuficiencia deba ser salvada por este Tribunal.

Tal como reitera el Tribunal Constitucional en los fallos recientes, los tratados internacionales, al no integrar el bloque de la constitucionalidad, no constituyen un estándar con el cual contrastar la validez de los actos jurídicos normativos, a los fines de resolver sobre su potencial constitucionalidad, y cualquier planteamiento sobre la contradicción entre un tratado y otras normas, por posible contravención al principio de jerarquía normativa, escapa al ámbito del control de constitucionalidad y debe ser resuelto en el caso concreto por los órganos jurisdiccionales competentes.

\subsection{La posición del Tribunal Supremo en los casos sometidos a su consideración}

Conforme al criterio establecido por el Tribunal Supremo en Sala de lo Contencioso-Administrativo, Sección 3, mediante Sentencia 2320/2012, de 12 de abril, ratificada de forma reiterada entre otras por la Sentencia 1/2014, de 13 de enero, se desestima el recurso contencioso-administrativo interpuesto por las empresas generadoras de energía a través de fuentes renovables, contra el artículo 7, apartado 3, y del Anexo III de la Orden ITC/3353/2010, de 28 de diciembre, y disposiciones regulatorias concordantes, así como contra el artículo primero, apartado diez, del Real Decreto 1565/2010, de 19 de noviembre, por ser conformes a derecho.

El Tribunal Supremo, al pronunciarse sobre la aplicación del Tratado sobre la Carta de la Energía, señaló lo siguiente:

En cuanto al Tratado sobre la Carta de la Energía y el Protocolo de la Carta de la Energía sobre la eficacia energética y los aspectos medioambientales relacionados, aprobados en nombre de la Comunidad Europea del Carbón y del Acero, de la Comunidad Europea y de la Comunidad Europea de la Energía Atómica por la Decisión del Consejo y de la Comisión de 23 de septiembre de 1997, contienen, en efecto, disposiciones sobre la protección de las inversiones en esta materia. Respecto de ellas las Partes Contratantes han de fomentar y crear condiciones estables, favorables y transparentes para los inversores extranjeros y 
les aplicarán el principio de nación más favorecida o el trato que concedan a sus propios inversores, según el régimen más favorable.

Aunque admitiéramos a efectos meramente dialécticos que - como interesan los recurrentes - el Tratado fuese aplicable a los inversores españoles respecto de las decisiones adoptadas por el Gobierno espańol, lo que no se aviene con las disposiciones de aquél, lo cierto es que la protección de las inversiones extranjeras a la que se refiere su artículo 10 lo es contra «medidas exorbitantes o discriminatorias», calificativos que no consideramos adecuados a la mera restricción a 30 años del período de disfrute de la tarifa regulada, en las condiciones y por los motivos ya expuestos, medida que se aplica por igual a todos los productores fotovoltaicos afectados. Mucho menos puede calificarse de «nacionalización, expropiación o medida o medidas de efecto equivalente a la nacionalización o a la expropiación», en los términos del artículo 13 del Tratado.

Y aun cuando el Tratado promueve que las Partes Contratantes fomenten y creen «condiciones estables, equitativas, favorables y transparentes para que los inversores de otras Partes Contratantes realicen inversiones en su territorio", la nota de «estabilidad» debe entenderse referida al marco regulatorio en su conjunto, no a una medida aislada de las que lo componen, y tampoco puede interpretarse en el sentido de que suponga la absoluta petrificación del régimen inicialmente aprobado cuando, como aquí ocurre, ha habido cambio de circunstancias relevantes y motivos justificadores de la modificación regulatoria aplicada a la tecnología fotovoltaica. Las inversiones en esta tecnología siguen estando protegidas y fomentadas en Espańa por un marco normativo sin duda favorable en su globalidad (además de tener la garantía del principio de rentabilidad razonable) incluso si la significación económica de alguna de las medidas ulteriores hubiera eventualmente implicado una muy limitada - y más bien hipotética, dada su eficacia plena para dentro de treinta añosdisminución de las previsiones de beneficios calculados inicialmente.

Dicho lo cual, la Sala no aprecia que existan razones para someter al Tribunal de Justicia una cuestión prejudicial. No consideramos, en efecto, que la medida objeto de recurso pudiera ser contraria al Derecho de la Unión Europea, tanto si tomamos como referencias normativas de contraste los principios de seguridad jurídica y protección de la confianza legítima o el artículo 16 de la Directiva 2009/28/CE cuanto si se entendiera que la Carta Europea de la Energía y el Protocolo tienen aquella dimensión en virtud de la ya citada Decisión del Consejo y de la Comisión de 23 de septiembre de 1997.

Del fallo parcialmente transcrito emergen dos ideas de importancia cardinal: una es que el Tratado sobre la Carta de la Energía no puede ser invocado como violado por los inversionistas nacionales, pues el mismo únicamente tiene como sujetos de protección a los inversionistas extranjeros, y la otra, que al efectuar el ejercicio teórico de contrastar el estándar de protección del Tratado sobre 
la Carta de la Energía con las normas adoptadas por el Estado, estas no se pueden considerar exorbitantes, ni discriminatorias, pues ellas se aplican por igual a todos los inversionistas que se encuentran regulados por ese régimen jurídico.

Posteriormente, el Tribunal Supremo en Sala de lo Contencioso-Administrativo, Sección 4, en Sentencia 66/2016, de 21 de enero, desestimó el recurso contencioso-administrativo interpuesto por la empresa generadora de energía a través de fuentes renovables, contra el acuerdo del Consejo de Ministros de fecha 22 de marzo de 2013, por el que se desestiman las reclamaciones de responsabilidad patrimonial formuladas por los daños y perjuicios causados a sus instalaciones de producción de electricidad, que tiene como fuente la energía solar fotovoltaica, por la entrada en vigor del Real Decreto 1565/2010, de 19 de noviembre, del Real Decreto Ley 14/2010, de 23 de diciembre, y de la Ley 2/2011, de 4 de marzo.

Más reciente, el Tribunal Supremo en Sala de lo Contencioso-Administrativo, Sección 3, en Sentencias 1265/2016 y 1266/2016, de 1 de junio —que utilizan como fundamento la Sentencia del Tribunal Constitucional 270/2015, de 17 de diciembre-, desestimaron los recursos contencioso-administrativos interpuestos por las empresas generadoras de energía, a través de fuentes renovables contra el Real Decreto 413/2014, de 6 de junio, por el que se regula la actividad de producción de energía eléctrica a partir de fuentes de energía renovables, cogeneración y residuos, y contra la Orden IET/1045/2014, de 16 de junio, por la que se aprueban los parámetros retributivos de las instalaciones tipo, aplicables a determinadas instalaciones de producción de energía eléctrica a partir de fuentes de energía renovables, cogeneración y residuos.

\section{LAS IMPLICACIONES DE LOS FALLOS RESPECTO A LOS GENERADORES MEDIANTE FUENTES RENOVABLES}

Hasta el presente se pueden advertir varias conclusiones, respecto a las sentencias de los tribunales nacionales ${ }^{18}$.

Los criterios jurisprudenciales desarrollados por el Tribunal Constitucional han desestimado la cuestionada constitucionalidad de los actos jurídicos que implementaron los recortes y que posteriormente eliminaron los incentivos a los generadores de energía eléctrica, a través de fuentes renovables fotovoltaicas; por el contrario, han considerado que tales medidas fueron razonables y acordes a las circunstancias en que se adoptaron.

Los criterios jurisprudenciales fijados por el Tribunal Supremo han avalado la legalidad de los actos jurídicos que establecieron los recortes y elimi-

18 Véanse algunos comentarios a las sentencias, en T. de la Quadra-Salcedo (2016: 76-79). 
naron los incentivos a los generadores de energía eléctrica, a través de fuentes renovables fotovoltaicas; desechando, en consecuencia, cualquier eventual responsabilidad de las administraciones públicas.

Se debe destacar que estos criterios podrían experimentar cambios, pues los votos particulares recientes demuestran que la disidencia con respecto a la posición mayoritaria se ha ido incrementando progresivamente y que esta es proclive a la idea de reconocer algún tipo de responsabilidad de las administraciones públicas, lo que por supuesto dependerá de las pretensiones que se formulen en el futuro.

Finalmente, dado que las pretensiones de reconocimiento de transgresión del Tratado sobre la Carta de la Energía no han prosperado ante los tribunales nacionales, corresponde a los inversionistas extranjeros formular sus reclamaciones ante los tribunales arbitrales para que sean estos quienes resuelvan conforme a lo que reconoce el Tratado, sobre la pretendida violación y consecuente responsabilidad del Estado. A este asunto se dedicará el análisis del laudo que se hará a continuación, que resulta ser el primero respecto a España en que se decide un conflicto en aplicación del Tratado.

\section{EL LAUDO ARBITRAL QUE APLICA EL TRATADO SOBRE LA CARTA DE LA ENERGÍA}

En este epígrafe se analizará el laudo del arbitraje 062/2012, recaído en el caso Charanne B.V. y Construction Investments S.A.R.L. contra el Reino de España, emitido el día 21 de enero de 2016, expedido por el Tribunal Arbitral del Instituto de Arbitraje de la Cámara de Comercio de Estocolmo, integrado por el presidente Alexis Mourre y los árbitros Guido Santiago Tawil y Claus von Wobeser.

La disputa entre las partes surgió como consecuencia de que una vez establecidas las reglas del régimen especial en la generación de energía eléctri$\mathrm{Ca}^{19}$, con el objetivo de fomentar el aprovechamiento de las fuentes de energías renovables - en el caso concreto la solar fotovoltaica-, a través del otorgamiento de incentivos y subvenciones estatales — que estimularon a los inversionistas a participar en el sector-, se modificó el régimen regulatorio esta-

19 J. M. Nebreda Pérez (2009), Aspectos jurídicos de la producción eléctrica en régimen especial, Madrid: Thomson-Civitas, págs. 5-70; I. González Ríos (2011), Régimen Jurídico-Administrativo de las Energías Renovables y de la Eficiencia Energética, Pamplona: Aranzadi Thomson-Reuters, págs. 203-264. 
bleciendo unas condiciones menos ventajosas que las iniciales ${ }^{20}$, lo que motivó las reclamaciones de los inversionistas al Estado receptor de la inversión ${ }^{21}$.

Seguidamente se precisarán las pretensiones expuestas por las partes ante el Tribunal Arbitral.

\section{LAS PRETENSIONES DE LAS PARTES}

Los demandantes son las sociedades mercantiles Charanne B.V. y Construction Investments S.A.R.L., cuyos representantes formularon varias pretensiones que se resumen a continuación:

1. Que se declare que el demandado ha incumplido del Tratado sobre la Carta de la Energía y en concreto que violó el artículo 13, al expropiar las inversiones de los demandantes sin una compensación, pronta, justa, adecuada y efectiva; que incumplió el artículo 10.1, que contiene la obligación de garantizar a los inversionistas un trato justo y equitativo; y que incumplió el artículo 10.12, que contempla la obligación de establecer en el derecho nacional los medios eficaces para la tramitación de demandas y el ejercicio de derechos.

2. Solicitan se condene al demandado a pagar las sumas reclamadas por concepto de indemnización, con los respectivos intereses, mientras no se proceda al pago total de la condena.

3. Subsidiariamente, en el caso de que no se hubiese condenado al demandado a indemnizar por las cantidades antes mencionadas, que se le condene a pagar las cantidades que determinan a su favor, por concepto de violación de la obligación establecida en el artículo 10.12 del Tratado, así como que conceda cualquier otra reparación que considere apropiada.

20 I. Ruiz Olmos y F. Delgado Piqueras (2014), La nueva regulación legal de las energías renovables: del régimen especial al régimen especifico; J. F. Alenza García (dir.), La regulación de las energías renovables ante el cambio climático, Pamplona: Thomson-Reuters Aranzadi, págs. 59-96.

21 Estos reclamos fueron formulados contra España, Italia, República Checa — desde el 15 de abril de 2016, se denomina Chequia_, Países Bajos, Alemania, Chipre, Luxemburgo y el Reino Unido. E. Bonafé y M. Gökçe (2016), «Escalated interactions between EU energy law and the Energy Charter Treaty", Journal of World Energy Law and Business, 9 (págs. 185-186). 
4. Que condene al demandado al pago de los costos y gastos que se hayan incurrido en el arbitraje, incluidos los costos y gastos del Tribunal Arbitral y del Instituto de Arbitraje de la Cámara de Comercio de Estocolmo, así como a reembolsar a los demandantes todos los gastos en que hayan incurrido como consecuencia del arbitraje, incluyendo los honorarios de abogados y expertos.

El demandado es el Reino de España, que a través de sus representantes expuso sus defensas previas y de fondo en los términos siguientes:

1. Que se desestime las pretensiones de los demandantes por ser inadmisibles, en virtud de considerar que el arbitraje devino sin objeto y por carecer el Tribunal Arbitral de jurisdicción sobre el asunto.

2. Subsidiariamente, en el supuesto negado de que el Tribunal resuelva que tiene jurisdicción para conocer de la controversia, que desestime todas las pretensiones de las demandantes en lo concerniente al fondo, pues el demandado no ha incumplido el Tratado sobre la Carta de la Energía.

3. Subsidiariamente, que se desestimen todas las pretensiones resarcitorias de los demandantes, en virtud de que ellos no han experimentado daño alguno, como consecuencia de las decisiones adoptadas por el demandado.

4. Que condene a los demandantes al pago de las costas y gastos que se deriven del arbitraje, incluidos los gastos administrativos de la Cámara de Comercio de Estocolmo, los honorarios de los árbitros, de los representantes del demandado, de los peritos y de los asesores, con la inclusión de una tasa de interés razonable desde la fecha en que tales costos se produzcan y hasta la fecha de su efectivo pago.

Precisados los límites de la controversia, se analizarán las razones expuestas por el Tribunal Arbitral para resolver el fondo, pues los aspectos procesales resultan menos relevantes, a los fines de la aplicación del Tratado sobre la Carta de la Energía.

\section{LA FUNDAMENTACIÓN DEL LAUDO}

El Laudo comienza por rechazar el alegato de inadmisibilidad del arbitraje por pérdida sobrevenida del objeto e inmediatamente procede a analizar los argumentos sobre el fondo. A continuación se expondrán los fundamentos del Laudo en el siguiente orden: en primer lugar, se analiza el posible incum- 
plimiento de la existencia de medios eficaces para la tramitación de las demandas (2.1); en segundo lugar, se explicará la denuncia de expropiación indirecta (2.2); en tercer lugar, se evaluará el supuesto incumplimiento del trato justo y equitativo (2.3), en las dos posibles manifestaciones que se alegaron del mismo: el desconocimiento de las expectativas legítimas (a) y el incumplimiento de la interdicción de retroactividad (b).

\subsection{Los medios eficaces para la tramitación de demandas}

El artículo 10.12 del Tratado sobre la Carta de la Energía establece que: «Las Partes Contratantes se asegurarán de que su derecho nacional proporciona medios eficaces para la tramitación de demandas y el ejercicio de derechos en relación con inversiones, acuerdos de inversión y autorizaciones de inversión».

Los demandantes consideran que el demandado, al modificar las condiciones jurídicas que existen al momento en que se hicieron las inversiones, violó esta norma del Tratado, pues denuncian que en el derecho nacional no es posible presentar recursos contencioso-administrativos contra tales actos jurídicos.

El Tribunal Arbitral señala que el estándar de medios eficaces supone que los Estados establezcan un marco legal que garantice a los inversores recursos eficaces para la realización y protección de las inversiones, pero no impone obligación alguna respecto a la organización del sistema judicial, por lo que resulta suficiente que exista un sistema adecuado de leyes e instituciones que funcionen de manera efectiva ${ }^{22}$.

Dado que existe la posibilidad de que el inversor que se considera afectado cuestione la validez de los actos jurídicos ante los órganos jurisdiccionales ordinarios y que de ser el caso, estos planteen al Tribunal Constitucional la cuestión de inconstitucionalidad, a lo que se suma la posibilidad de formular la demanda de responsabilidad patrimonial, previa reclamación administrativa ante la autoridad responsable, el Tribunal Arbitral considera que tales vías son suficientes para cumplir con la obligación de proporcionar medios eficaces $^{23}$.

Hay que tener presente que el estándar de medios eficaces exigido por el derecho internacional, no puede llegar a dictarle al Estado las modalidades precisas del sistema de recursos, obligándolo, por ejemplo, a establecer un sistema de control directo de la constitucionalidad de sus actos de naturaleza

22 Párr. 470.

23 Párrs. 471-472. 
legislativa. La ausencia de tal modalidad de control de la constitucionalidad no materializa una violación del estándar de medios suficientes, en la medida en que existen recursos tanto de control de constitucionalidad - aunque sea de manera incidental — como para obtener la compensación de los daños y perjuicios ${ }^{24}$.

En razón de lo anterior, el Tribunal Arbitral rechaza los alegatos de los demandantes, sobre la violación del estándar de medios eficaces ${ }^{25}$.

\subsection{La expropiación indirecta}

El artículo 13.1 del Tratado sobre la Carta de la Energía dispone respecto a las expropiaciones que:

1) Las inversiones de los inversores de una Parte Contratante en el territorio de otra Parte Contratante no serán objeto de nacionalización, expropiación o medida o medidas de efecto equivalente a la nacionalización o a la expropiación (a las cuales se aludirá en lo sucesivo como «expropiación»), excepto si dicha expropiación se lleva a cabo:

a) por un motivo de interés público;

b) de manera no discriminatoria;

c) con arreglo al debido procedimiento legal; y

d) mediante el pago de una indemnización rápida, adecuada y efectiva.

El importe de la indemnización equivaldrá al justo valor de mercado de la inversión expropiada inmediatamente antes de que el anuncio de la expropiación o de la intención de llevar a cabo la expropiación hubiese afectado al valor de la inversión (en lo sucesivo denominado «fecha de valoración»).

Este justo valor de mercado se expresará, a elección del inversor, en una divisa libremente convertible, basándose en el tipo de cambio existente en el mercado para esta divisa en la fecha de valoración. La indemnización incluirá intereses según un tipo comercial fijado con arreglo a criterios de mercado, desde la fecha de la expropiación hasta la del pago.

Los demandantes denuncian que los actos jurídicos expedidos por el demandado en 2010 generan un «brutal impacto económico causado a la rentabilidad de la actividad desarrollada" por la empresa mercantil en la que poseen acciones, por lo que consideran que ello constituye «una expropiación

24 Párr. 472

25 Párr. 474. 
de una parte sustancial del valor y de los rendimientos de la inversión». Por tanto, señalan que la afectación al valor económico de la inversión, aunque no se haya visto afectada la titularidad de las acciones, es suficiente para caracterizar una expropiación indirecta, pues no es necesaria «la destrucción total de la inversión o una pérdida de control, sino que una interferencia significativa en el disfrute de la inversión o su beneficio pueden ser suficientes».

Es preciso señalar que, conforme al Tratado, la inversión realizada por los demandantes consiste en una participación en acciones en una sociedad mercanti ${ }^{26}$, aunque los demandantes sostienen haber invertido en rendimien$\operatorname{tos}^{27}$, lo que les lleva a considerar que al afectarse los flujos de caja futuros de la empresa, los actos jurídicos adoptados produjeron una expropiación indirecta, pues al reducirse los rendimientos, estos quedaron expropiados.

El Tribunal Arbitral no comparte tal argumentación, pues considera que el objeto de la inversión no fueron los rendimientos, sino las acciones en la empresa y que conforme argumenta el demandado, la inversión protegida por el Tratado debe estar en posesión o control del inversor y los demandantes no poseen, ni controlan, los rendimientos futuros de la empresa, los cuales no constituyen derechos incorporados a su patrimonio ${ }^{28}$.

El Tratado prohíbe tanto las medidas expropiatorias como aquellas de efecto equivalentes —expropiación indirecta o creeping expropriation ${ }^{29}$ Siendo la expropiación una toma de posesión que implica una privación de la propiedad, para considerar que una expropiación es indirecta se debe analizar si las medidas adoptadas por el demandado tuvieron el efecto de privar total o parcialmente al inversor de sus derechos como accionista de la empresa mercantil ${ }^{30}$.

Considera el Tribunal Arbitral que el estándar de expropiación indirecta establecido por el derecho internacional implica una afectación sustancial de los derechos de propiedad del inversor, que puede consistir en una efectiva privación de todo o parte de los bienes objeto de la inversión o en una pérdida

26 Artículo 1.6.b) del Tratado sobre la Carta de la Energía.

27 Artículo 1.6.e) del Tratado sobre la Carta de la Energía.

28 Párr. 459.

29 Y. Nouvel (2002), «Les mesures équivalant à une expropriation dans la pratique récente des tribunaux arbitraux", Revue générale du droit international public, v. 106, págs. 79-102; L. Y. Fortier y S. L. Drymer (2004), «Indirect expropriation in the law of international investment: I know when I see it, or caveat investor", ICSID Review: Foreign Investment Journal, v. 19, págs. 293-327; J. A. Muci Borjas (2007), El derecho administrativo global y los tratados bilaterales de inversión (BITs), Caracas: Editorial Jurídica Venezolana, págs. 171-181.

30 Párr. 460. 
de valor, que pueda ser equivalente por su magnitud, a una privación de la inversión ${ }^{31}$.

Sin embargo, constituye un hecho admitido que los demandantes siguen siendo titulares de sus acciones en la empresa, no existen alegatos ni evidencias de que sus derechos como accionistas hayan sido limitados o afectados de alguna manera por los actos jurídicos adoptados por el demandado. Además, tampoco es un hecho controvertido que la empresa se encuentra operando y produciendo ganancias, ni fue alegado que aunque los actos jurídicos hayan afectado la rentabilidad de la empresa, esta haya sido privada de todo o parte de sus bienes o activos ${ }^{32}$.

El único aspecto controvertido es la disminución de la rentabilidad de la empresa y por consiguiente del valor de las acciones. Por ello, los demandantes sostienen que una expropiación indirecta puede ser producto de una pérdida de valor de una inversión o de una pérdida de control sobre la misma. Ahora bien, para que una pérdida de valor sea equivalente a una expropiación, tiene que ser de tal magnitud que equivalga a una privación de propiedad ${ }^{33}$.

Considera el Tribunal Arbitral que aun cuando la rentabilidad de la empresa pudiera haber sido seriamente afectada como alegan los demandantes, dicha afectación no es por sí misma suficiente para constituir una expropiación, pues de admitirse tal argumento, se llegaría al resultado de que cualquier acto jurídico que afecte la rentabilidad de una sociedad pudiera considerarse expropiatorio, en cuanto pudiera producir una disminución de las ganancias de la misma y por consiguiente de su valor. En criterio del Tribunal Arbitral, esto no es admisible, pues para que un acto jurídico pueda ser considerado como equivalente a una expropiación, los efectos que producen deben ser de tal magnitud que se pueda considerar que el inversor ha sido privado, total o parcialmente, de su inversión, pero una disminución del valor de las acciones objeto de la inversión no puede considerarse una expropiación indirecta, a menos que la pérdida de valor sea tal que se pueda considerar equivalente a una privación de propiedad ${ }^{34}$.

Sostiene el Tribunal Arbitral que de admitirse el planteamiento propuesto por los demandantes, aunque la reducción de la rentabilidad pudiese haber tenido serias consecuencias económicas y financieras, no es de tal magnitud para considerar que el valor de la inversión haya quedado destruido e incluso destaca que aunque se haya reducido, los demandantes reconocen que la rentabilidad de las plantas se mantuvo positiva ${ }^{35}$.

\footnotetext{
31 Párr. 461.

32 Párr. 462.

33 Párr. 464.

34 Párr. 465.

35 Párr. 466.
} 
Conforme a lo anterior, considera el Tribunal Arbitral que los demandantes no han probado que los actos jurídicos expedidos por el demandado hayan tenido efecto equivalente a una expropiación ${ }^{36}$.

\subsection{El trato justo y equitativo}

En lo concerniente a la denuncia de violación del trato justo y equitativo, el artículo 10.1 del Tratado sobre la Carta de la Energía dispone que:

De conformidad con las disposiciones del presente Tratado, las Partes Contratantes fomentarán y crearán condiciones estables, equitativas, favorables y transparentes para que los inversores de otras Partes Contratantes realicen inversiones en su territorio. Entre dichas condiciones se contará el compromiso de conceder en todo momento a las inversiones de los inversores de otras Partes Contratantes un trato justo y equitativo. Estas inversiones gozarán asimismo de una protección y seguridad completas y ninguna Parte Contratante perjudicará en modo alguno, mediante medidas exorbitantes o discriminatorias, la gestión, mantenimiento, uso, disfrute o liquidación de las mismas. En ningún caso podrá concederse a estas inversiones un trato menos favorable que el exigido por el derecho internacional, incluidas las obligaciones en virtud de los tratados. Toda Parte Contratante cumplirá las obligaciones que haya contraído con los inversores o con las inversiones de los inversores de cualquier otra Parte Contratante.

Los demandantes denuncian que el demandado ha vulnerado el estándar de trato justo y equitativo al modificar de modo inesperado el régimen regulatorio y económico aplicable a sus inversiones y por ende las expectativas legítimas (a), así como que tales actos jurídicos son violatorios de sus derechos, al ser retroactivos (b).

a) El desconocimiento de las expectativas legítimas

En lo relacionado con el desconocimiento de las expectativas legítimas, los demandantes consideran que el demandado violó el Tratado al modificar de un modo inesperado el régimen regulatorio y económico que les era aplicable, vulnerando las expectativas legítimas y que al alterar el marco jurídico generó que su inversión quedase librada a inestabilidad regulatoria que se mantendría hasta el momento de formular sus alegatos. Sostiene que se trata de una ofensiva regulatoria en el período 2010-2013, que generaron ese contexto de inestabilidad y de falta de claridad que contraviene el artículo 10.1 del Tratado.

36 Párr. 467. 
El Tribunal Arbitral considera que habiendo circunscrito la controversia a las normas regulatorias expedidas en 2010, no debe pronunciarse sobre las producidas con posterioridad, pues escapan al objeto del debate ${ }^{37}$ y al resolver sobre aquellas que incumbe al objeto de conflicto, señala que no puede concluir que el demandado violó la obligación de estabilidad regulatoria ${ }^{38}$; y en lo concerniente a la falta de claridad del marco regulatorio, sostiene que ello no puede ser valorado, pues también excede el objeto del arbitraje, al referirse a las normas expedidas en $2013^{39}$.

Considera el Tribunal Arbitral que con base en el principio de buena fe del derecho internacional, un Estado no puede inducir a un inversor a realizar una inversión, generando expectativas legítimas, para luego desconocer los compromisos que hayan generado tales expectativas ${ }^{40}$.

Partiendo de esta premisa se analiza el argumento según el cual el marco normativo existente al momento de la inversión generó expectativas legítimas y si el cambio del marco regulatorio las ha desconocido. Al respecto considera el Tribunal que no existen compromisos específicos adoptados personalmente frente a los demandantes, como una cláusula de estabilización o cualquier tipo de declaración que el Estado hubiese efectuado a los inversores y que estos fuesen sus destinatarios, en la que asumiera que el marco regulatorio existente al momento de la inversión no cambiaría ${ }^{41}$.

Agrega el Tribunal que el marco normativo existente al momento de la inversión no puede constituir o ser equivalente a un compromiso específico, pues aun estando dirigido a un grupo limitado de inversores, no lo convierte en compromisos concretos dirigidos a cada uno de ellos. Tales normas, por su alcancen específico, no pierden la naturaleza general que caracteriza a los actos legislativos o reglamentarios ${ }^{42}$.

Precisado lo anterior, considera que la comprobación de la existencia de vulneración de las expectativas legítimas del inversor debe fundarse en un estándar o análisis objetivo, por lo que no resulta suficiente la mera convicción subjetiva que pudo tener el inversor al momento de realizar la inversión. A ello se suma que la aplicación del principio se encuentra condicionada a que la expectativa haya sido razonable en el caso concreto, siendo relevante las representaciones eventualmente realizadas por el Estado para inducir la inversión ${ }^{43}$,

\footnotetext{
37 Párr. 482.

38 Párr. 484.

39 Párr. 485.

40 Párr. 486.

41 Párr. 490.

42 Párrs. 492-493.

43 Párr. 495.
} 
es decir, lo relevante es saber si el marco regulatorio existente al momento de la inversión era capaz de generar la expectativa legítima protegida por el derecho internacional de que el mismo no sería posteriormente modificado y del análisis efectuado se puede concluir que un inversor no podía tener tal expectativa en ausencia de compromiso concreto, respecto a que la regulación existente no sería modificada ${ }^{44}$.

Ello es así porque de admitirse la existencia de la pretendida expectativa, habría que inferir que el marco regulatorio aplicable se debe mantener congelado, aunque las circunstancias hayan cambiado, lo que conduciría a admitir que cualquier cambio en la tarifa o en el horario supondría una violación del derecho internacional $y$, añade, que incluso hasta los propios demandantes reconocieron no haber tenido la expectativa legítima de que el marco regulatorio iba a permanecer inmutable ${ }^{45}$.

Para considerar que los actos jurídicos eran violatorios de las expectativas legítimas del inversor, las medidas regulatorias no debieron haber sido razonablemente previsibles en el momento de la inversión, pero en el asunto sometido a arbitraje, los demandantes podían prever fácilmente la posibilidad de modificaciones al marco regulatorio, pues ello estaba previsto en la legislación nacional ${ }^{46}$. Este es el nivel de diligencia que se esperaría de un inversionista extranjero en un sector altamente regulado como el energético, que impone insoslayablemente un análisis previo y exhaustivo del marco jurídico aplicable al sector, antes de proceder a realizar la inversión ${ }^{47}$.

Establecido lo anterior, procede analizar si los actos jurídicos modificatorios del régimen de inversión no son en sí mismos violatorios de los estándares de trato justo y equitativo.

Debe advertirse que los demandantes argumentan que las expectativas legítimas resultan frustradas, aun en ausencia de compromisos específicos, cuando el Estado realiza actos jurídicos incompatibles con el criterio de razonabilidad económica, con el interés público o con el principio de proporcionalidad. Al respecto, el Tribunal Arbitral acepta que el inversor tiene la expectativa legítima de que el Estado, al modificar la regulación existente al momento de la inversión, no actuará de manera irrazonable, contraria al interés público o desproporcionada, que son los estándares que deberá analizar antes de finalizar este punto ${ }^{48}$.

\footnotetext{
44 Párrs. 498-499.

45 Párr. 503.

46 Párr. 505.

47 Párr. 507.

48 Párrs. 513-515.
} 
En cuanto al principio de proporcionalidad, señala que este se considera satisfecho en la medida en que las modificaciones no sean caprichosas o innecesarias, y que no lleguen a suprimir de manera imprevisible y repentina las características esenciales del marco regulatorio existente ${ }^{49}$, lo que se mantiene bajo la reforma de $2010^{50}$, que ha implementado ajustes y adaptaciones que no suprimieron las características fundamentales del marco regulatorio existente, pues las empresas operadoras mantuvieron el derecho a percibir la tarifa y la posibilidad de vender la totalidad de la generación de energía de manera prioritaria dentro del sistema, por lo que no se violó la expectativa legítima conforme al derecho internacional ${ }^{51}$.

En lo referido al principio de racionalidad económica, el Tribunal Arbitral estima que tanto la limitación de las tarifas a un período máximo como la limitación temporal de horas elegibles responden a criterios objetivos y, aunque pueden perjudicar los intereses económicos de los generadores, no pueden ser consideradas como irracionales o arbitrarias $^{52}$.

En lo concerniente al principio del interés público, la adopción de medidas orientadas a limitar el déficit de tarifa y la evolución del precio no resultan contrarias a este principio, ni son arbitrarias e irracionales, a lo que se suma que no se ha aportado prueba en tal sentido ${ }^{53}$ y tampoco se ha producido discriminación con los generadores que aprovechan las fuentes renovables eólicas, pues el Estado puede aplicar reglas diferentes a sectores industriales distintos, sin que se materialice la violación a la obligación de no discriminación contemplada en el derecho internacional ${ }^{54}$.

Tampoco aprecia el Tribunal que las normas cuestionadas fueren injustas e incoherentes o hubiesen sido adoptadas en violación del debido proceso legislativo o reglamentario ${ }^{55}$.

Según lo antes expresado, el Tribunal Arbitral concluye que no ha ocurrido un desconocimiento de la obligación de otorgar un trato justo y equitativo ${ }^{56}$.

b) La violación de la interdicción de retroactividad

\footnotetext{
Párr. 517.

Párr. 519.

1 Párr. 533.

2 Párr. 534.

53 Párr. 536.

54 Párr. 538.

55 Párr. 539

56 Párr. 540.
} 
En lo concerniente a la denuncia de violación de la interdicción de retroactividad, los demandantes sostienen que al expedir los actos jurídicos que modificaron las reglas contenidas al momento en que efectuaron su inversión y proceder a aplicarlas de manera inmediata se afectaron sus derechos adquiridos, al alterarse las condiciones de equilibrio económico conforme a las cuales habían decidido invertir, lo que constituye una regulación retroactiva incompatible con el citado artículo 10.1 del Tratado sobre la Carta de la Energía. Consideran que como inversionistas de la empresa generadora han sido afectados, pues esta tenía un auténtico activo incorporado a sus instalaciones e integrado a su patrimonio, que era susceptible de valoración económica y transmisible con la instalación.

El Tribunal Arbitral no acepta el argumento de la pretendida retroactividad de los actos jurídicos expedidos en 2010 por el demandado y señala que no existe ningún compromiso contractual con los demandantes, por lo que procede a valorar cuál es el alcance de la potestad del Estado para modificar con aplicación inmediata las normas reglamentarias de aplicación general ${ }^{157}$.

Es así como el Tribunal ratifica que la obligación de otorgar un trato justo y equitativo no implica que el marco regulatorio debe mantenerse inalterado para todas las empresas mercantiles con respecto a sus instalaciones a lo largo de su vida útil, pues aceptar esa hipótesis significaría congelar el marco regulatorio, quedando limitado cualquier cambio de la regulación a nuevas empresas e instalaciones establecidas con posterioridad a dichos cambios ${ }^{58}$.

La inscripción de la empresa operadora en un registro constituye un requisito administrativo para realizar la venta de energía, pero ello no atribuye un derecho adquirido a una determinada retribución ${ }^{59}$.

El Tribunal considera que habiéndose aplicado inmediatamente a su entrada en vigor los nuevos actos jurídicos que modificaron el régimen existente al momento que se hicieron las inversiones en las empresas mercantiles, ello no supuso aplicación retroactiva a los períodos de operación anterior y por tanto no existe principio alguno de derecho internacional — ni ha sido demostrado por los demandantes-, salvo en el supuesto de que existan compromisos específicos como los que se derivarían de un contrato, que prohíba a un Estado adoptar las medidas regulatorias con efecto inmediato, respecto a situaciones en curso $^{60}$.

Con fundamento en lo expuesto, el Tribunal Arbitral desestima los argumentos de los demandantes, según los cuales la aplicación inmediata de los

\footnotetext{
57 Párrs. 544-545.

58 Párr. 546.

59 Párr. 547.

60 Párr. 548.
} 
actos jurídicos expedidos en 2010 constituyen una violación del artículo 10.1 del Tratado ${ }^{61}$.

\section{LA DECISIÓN}

El Tribunal Arbitral luego de analizar detenidamente los alegatos formulados por los demandantes y el demandado, resuelve asumir la competencia para conocer del conflicto; rechaza la totalidad de las pretensiones formuladas por los demandantes y los condena de manera conjunta y solidaria a pagar los costos del arbitraje, así como el impuesto sobre el valor agregado, de ser procedente; los costos razonables en que incurrió el demandado, los cuales generarán los intereses a favor de este a la tasa legal en vigor en Espańa, a partir de la fecha del laudo y hasta el momento de su efectivo pago $^{62}$.

\section{EL VOTO DISIDENTE}

El árbitro Guido Santiago Tawil manifestó las razones por las cuales no comparte los argumentos expresados en el Laudo y que llevan a la conclusión de rechazar las pretensiones de los demandantes, las cuales se resumen seguidamente.

Comienza por reconocer la cuestionada competencia del Tribunal Arbitral para resolver el conflicto $^{63}$, al amparo del Tratado sobre la Carta de la Energía y también reconoce que la mayoría del Tribunal aplica correctamente el estándar de expropiación indirecta, que exige una afectación sustancial de los derechos de propiedad, por lo que resulta correcto concluir que no hubo expropiación indirecta del demandado ${ }^{64}$.

No obstante, manifiesta su desacuerdo con respecto al alegato de las expectativas legítimas que integran el estándar de trato justo y equitativo que reconoce el Tratado ${ }^{65}$.

Partiendo de la premisa que la potencial vulneración de las expectativas legítimas del inversor debe valorarse sobre la base de un análisis objetivo y no de mera apreciación subjetiva que pudo tener el inversor al efectuar la inversión, considera que la aplicación de este criterio se debe efectuar en cada caso y que

\footnotetext{
61 Párr. 549.

62 Párr. 573.

63 Párr. 1.

64 Párr. 2.

65 Párr. 3.
} 
debe considerarse que la expectativa ha sido razonable en el caso concreto $^{66}$; $\sin$ embargo, la generación de expectativas legítimas en un inversor no se encuentra limitada únicamente a la existencia de un compromiso específico de naturaleza contractual o basado en declaraciones específicas otorgadas por el Estado receptor, pues ella puede evidenciarse del ordenamiento jurídico vigente al momento de realizarse la inversión ${ }^{67}$.

Conforme a esta idea considera que el marco normativo especial establecido por el demandado respecto a la fijación del cobro de tarifas y la temporalidad de la vigencia de las mismas, considerado junto a otros documentos, dan el contexto objetivo para que los demandantes resolviesen realizar la inversión, en el entendido de que sería mantenido y no alterado ${ }^{68}$.

Ese marco normativo no estaba dirigido a una generalidad indeterminada o imprecisa, sino a un número reducido de potenciales destinatarios que contaban con los recursos económicos para hacerlo ${ }^{69}$, a lo que se suma la temporalidad de esta normativa sujeta a un plazo de caducidad, por lo que considera que ambas condiciones constituyen el establecimiento y la aceptación de expectativas legítimas en favor de los demandantes ${ }^{70}$.

Considera que no existe un derecho adquirido al mantenimiento de un régimen jurídico general determinado, ni tampoco existe la expectativa legítima a la estabilidad de las leyes y reglamentos, por lo que el Estado siempre conserva intacta su potestad reglamentaria y puede modificarlas, incluso habiendo otorgado cláusulas de estabilidad. No obstante, si en el ejercicio de tal potestad el Estado afecta derechos adquiridos o expectativas legítimas, debe indemnizar a los afectados por los perjuicios causados ${ }^{71}$.

En razón de lo anterior concluye señalando, que:

[...] cuando un inversor cumple con todos los requisitos establecidos por la normativa vigente para ser acreedor a un derecho específico y determinado, su desconocimiento posterior por parte del Estado receptor de la inversión viola una expectativa legítima. El Reino de España se encontraba facultado para modificar o eliminar el régimen de promoción instaurado, no existiendo el riesgo de congelamiento, petrificación o inmutabilidad del marco regulatorio. No obstante ello, si al modificar el beneficio otorgado a quienes ya habían invertido en función de ese régimen especial —estableciendo en el caso una

\footnotetext{
66 Párr. 4.

67 Párr. 5.

68 Párr. 6.

69 Párr. 8.

70 Párr. 9.

71 Párr. 11.
} 
limitación al número de horas de producción y los años con derecho a tarifaprovocaba un perjuicio sin establecer una compensación adecuada, estaría violando las expectativas legítimas creadas y, con ello, el trato justo y equitativo protegido en el artículo 10 del $\mathrm{TCE}^{72}$.

\section{EL OTRO LAUDO ARBITRAL QUE APLICA EL TRATADO SOBRE LA CARTA DE LA ENERGÍA}

El Laudo arbitral recaído en el caso Isolux Infrastructure Netherlands B.V. contra el Reino de España, emitido en la primera quincena de julio de $2016^{73}$, expedido por el Tribunal Arbitral del Instituto de Arbitraje de la Cámara de Comercio de Estocolmo, integrado por el presidente Yves Derains y los árbitros Guido Santiago Tawil y Claus von Wobeser, constituye la segunda victoria consecutiva del demandado.

El asunto trata de una sociedad mercantil española que también consideró que obtendría un mejor resultado en el arbitraje internacional que intentando una demanda ante los tribunales nacionales, y resolvió valerse de una filial holandesa para solicitar el arbitraje.

La disputa entre las partes surgió por las sucesivas reformas regulatorias que han sido explicadas en este trabajo, que se tradujeron en las rebajas de los subsidios o las primas para la generación de electricidad, mediante el aprovechamiento de fuentes renovables y además por considerar que una vez realizada su inversión, el establecimiento de un impuesto del $7 \%$ a los ingresos de las empresas que generan electricidad con dichas fuentes le afectaba.

Dado que el laudo se encuentra sujeto a condiciones de confidencialidad, no existe manera de conocer todas las pretensiones formuladas y, en función de ello, los términos de lo resuelto por el Tribunal Arbitral ${ }^{74}$.

\section{CONSIDERACIONES FINALES}

La situación que se ha analizado con la aplicación del Tratado sobre la Carta de la Energía a los inversionistas que optaron por participar en el mercado de la generación de energías a través de fuentes renovables fotovoltaicas, constituye un precedente a nivel nacional, que genera mucha incertidumbre

\footnotetext{
Párr. 12.

73 http://www.elconfidencial.com/empresas/2016-07-13/laudo-espana-arbitraje-internacional-recorte-renovable_1232050/

74 http://investmentpolicyhub.unctad.org/ISDS/Details/564
} 
en los inversionistas sobre el contexto de estabilidad —lato sensu—, en el cual pueden realizar sus inversiones futuras.

Los tribunales nacionales en los casos resueltos concluyeron que los actos jurídicos adoptados para modificar o extinguir el régimen normativo que estimuló la inversión se encontraban suficientemente justificados y que no eran imprevisibles o irrazonables.

El conflicto resuelto en el arbitraje constituye un precedente al que deberá hacerse seguimiento, para ver la evolución que pueda producirse respecto a los otros casos pendientes de arbitrajes en aplicación del Tratado ${ }^{75} \mathrm{y}$, en concreto, de aquellos que atañen al Estado español ${ }^{76}$, que rondan un tercio -30 casos de arbitraje- del centenar pendientes de resolución ${ }^{77}$.

75 En la doctrina científica italiana, se considera que el Laudo del arbitraje 062/2012 es un antecedente irrelevante por tener un alcance limitado a unas medidas que fueron finalmente derogadas, además que ello fue precisado así en el Laudo por el Tribunal Arbitral, al aclarar que no prejuzga sobre otros asuntos no comprendidos en los límites de la controversia. Se consideran poco convincentes algunos argumentos formulados sobre el análisis del Tratado de la Carta de la Energía y se concluye que: «Insomma, il lodo 'Charanne' non pone fine alle molteplici questioni qui discusse. Occorrerà attendere i prossimi lodi emessi nei molti procedimenti tuttora pendenti per formarsi un quadro d'insieme, dal quale comprendere come si assesterà la giurisprudenza abritrale nella materia». A. de Luca (2016), «Lodo favorevole alla spagna a conclusione del primo degli investment arbitrations sorti da impianti fotovoltaici: un precedente rilevante?», $D i$ ritto del Commercio Internazionale, Anno XXX, Fasc. 1, págs. 272-275.

En la doctrina científica espańola, se reconoce que el Laudo del arbitraje Charanne «[...] supone indudablemente un claro precedente para los más de veinte arbitrajes que tiene planteados nuestro país por los recortes a las renovables, [que] no es extrapolable al resto de las demandas, puesto que este laudo solo se pronuncia sobre las modificaciones legislativas del año 2010 en el sector fotovoltaico, que tienen un alcance mucho más limitado que las de los años 2013 y 2014. Por tanto, las expectativas de los inversores extranjeros de obtener decisiones arbitrales favorables se mantienen casi intactas». A. M. López Rodríguez y P. Navarro Rodríguez (2016), «Riesgo regulatorio en el sector de las energías renovables en Espańa y poliarquía normativa: distintas soluciones para un mismo problema», Riesgo Regulatorio en las energías renovables II (pág. 212), Pamplona: Thomson Reuters-Aranzadi.

77 Resulta importante tener presente que inspirado en el estándar de derecho internacional, establecido en el artículo 59 del Estatuto de la Corte Internacional de Justicia, el Laudo señala en el párrafo 542, que «[...] el Tribunal Arbitral no pretende prejuzgar de manera alguna las conclusiones a las que podría llegar otro tribunal arbitral con base en el análisis del conjunto de las normas adoptadas hasta la fecha, incluyendo las normas de 2013, que han quedado por elección de las Partes fuera del análisis sometido a este Tribunal». 
Esto también genera una enorme incertidumbre sobre el futuro desarrollo de las tecnologías limpias ${ }^{78}$ y el aprovechamiento eficiente de las fuentes de energías renovables, pues el riesgo regulatorio puede tornar más tímidos los progresos en $\mathrm{I}+\mathrm{D}+\mathrm{i}$ ante la inseguridad de retorno y de la rentabilidad razonable, que aspiran quienes invierten en ello.

Sin ninguna duda, cabe compartir la inquietud formulada por la doctrina científica respecto a que lo ocurrido supone el riesgo de que un juicio emitido en circunstancias excepcionales se constituya en el criterio de referencia para el enjuiciamiento en situaciones de normalidad ${ }^{79}$.

Finalmente, un aspecto que no debe soslayarse es que siendo los inversionistas españoles quienes lideran los principales grupos de inversión en Latinoamérica, es justamente desde allá donde se ha construido una doctrina jurídica - que cambiando lo que hay que cambiar, pero siempre en materia de protección de las inversiones-, le podría ser de utilidad a cualquier Estado en Latinoamérica para promover inversiones y en caso de verse obligado a modificar las condiciones iniciales de la inversión extranjera, podría librarse exitosamente de la responsabilidad patrimonial de indemnizar a estos inversionistas, siempre que siga estrictamente el guión que han hilvanado los juristas del Estado y que han aceptado tanto los tribunales nacionales como el tribunal arbitral en estos asuntos.

8 J. F. Alenza García (2016: 17-21).

79 I. del Guayo (2016), «La Carta Internacional de la Energía en 2015 y las energías renovables. A propósito del Laudo de 21 de enero de 2016», Cuaderno de Energía, 47, pág. 56. 
